\title{
Divergent Refugee and Tribal Cosmopolitanism in Dharamshala
}

\author{
STEPHEN CHRISTOPHER
}

\begin{abstract}
This article analyses the divergent, and occasionally overlapping, trajectories of Tibetan refugee and Gaddi tribal cosmopolitanism in Dharamshala, North India. In a place self-consciously branded as cosmopolitan, where Tibetan ethnocommodification is the primary symbolic currency, practices of inclusivity can broadly give way to Gaddi exclusions. Cosmopolitanism as an ordering ideology and set of intercultural competencies, often predicated on the dyadic relationship between Tibetan refugees and international tourists, propels Gaddi resentments and coarsens intergroup sociality. This does not mean, however, that Gaddis are forever consigned to tribal backwardness and reactionary forms of communal aspiration. Gaddis have forged an alternate, grounded cosmopolitanism based on cultural skills fostered through pastoral transhumance, seasonal labour migration corresponding with foreign tourists and ongoing ethnopolitical redefinition of what it means to be tribal itself. By seeing past utopian propaganda and dystopian exaggerations about Dharamshala, a richer tapestry of group relations emerges which reveals divergent cosmopolitanisms in the promotion of shared struggles for state recognition and cultural preservation.
\end{abstract}

Keywords: Scheduled Tribe Dalit (STD); ethno-commodification; mobility; Tibetan diaspora; Gaddi

In 1959, thousands of Tibetan refugees, together with the Dalai Lama, fled from the violent incorporation of their homeland by the Chinese People's Liberation Army and took refuge in India. Although the initial settlements were beset with hardship, Dharamshala, the home of the Dalai Lama and centre of Tibetan diasporic politics in North India, has emerged as the most translocal, deeply geopolitical, highly capitalistic and densely touristic destination anywhere in the Himalayas. ${ }^{1}$ The confluence of the Dalai Lama winning the Nobel Peace Prize in 1989, Hollywood adopting Tibetan independence as the cause

This article can be accessed at https:/ / doi.org/10.22439/ cjas.v38i1.6058. 
célèbre throughout the 1990s and jet-setting monks establishing global dharma centres irrevocably shaped the cosmopolitan contours of diasporic Tibetan life in the small mountain town. Moreover, favourable Indian legislation privileging Tibetans over other refugee communities (Bentz 2012) and the pragmatic extension of the patron/client dyad to exchange Tibetan Buddhism for international support have contributed to socioeconomic status inequalities favouring Tibetan refugees relative to their Indian neighbours, a mixed-caste tribal community called Gaddi, which is autochthonous to the region and traditionally engaged in transhumant pastoralism.

As this article explores, cosmopolitanism in Dharamshala is roughly synonymous with the intercultural competencies necessary to carve out an economic niche within an ethnically superdiverse tourist economy centred on the ethno-commodification of Tibetan Buddhism. ${ }^{2}$ While recent scholarship is sensitive to how economic interdependence underpins cosmopolitanism in McLeod Ganj, ${ }^{3}$ I argue that Gaddis and Tibetans, autochthonous hill tribals and internationally celebrated refugees, are not structurally equal subaltern actors in this overtly materialistic expression of cosmopolitanism. Tibetans in Dharamshala live in a world of international goodwill in which they have myriad opportunities to develop cosmopolitan competencies and materially benefit from symbolic capital - a world which Gaddis emphatically do not cohabitate. That does not mean, however, that Gaddis are forever consigned to tribal backwardness and reactionary forms of communal aspiration. Gaddis have forged an alternate cosmopolitanism by culturally adapting during the transhumant pastoral cycle, a lifeway that has diminishing popularity but remains a cultural touchpoint for Gaddi belonging. In the past two decades, Gaddi cosmopolitanism has involved seasonal migration throughout India seeking employment based on international tourism, and is undergoing ethnopolitical redefinition to include socially ostracised lower castes. This article analyses the different, and occasionally overlapping, trajectories of Tibetan and Gaddi cosmopolitanism and argues that cosmopolitanism predicated on cultural orientations for international engagement broadly excludes Gaddis and impedes intergroup sociality.

These dynamics play out in Dharamshala, a town that was once a Gaddi pastoral stopover between highland Chamba and the Kangra plains. Upper Dharamshala (McLeod Ganj) was known as the first or last social destination, depending on direction, for Gaddis crossing the Indrahar Pass. It was called Talu by Gaddis, a name derived from the 
raised stone platform (ticya $l \bar{a})$ around the central Deodar tree that gave shade and respite to shepherds. Some Gaddis maintain the naming convention primarily through its association with Talu wale ka goth, the pastureland sometimes visible on the cloud-covered mountaintop. Talu has successively transformed from shepherding midpoint to colonial hill station, ${ }^{4}$ to earthquake-ravaged Gaddi village to geopolitical hub of diasporic Tibetans and a globally recognised tourist destination. The few Gaddi shepherds who still intrepidly (or indifferently) graze within city limits do so with uncertainty about the privatisation of once-communal pasturelands and anxiety about being perceived as uncouth.

From these pastoral beginnings, a place of shaded stillness before or after a long journey, Dharamshala has morphed into the most translocal, deeply geopolitical, highly capitalistic and touristic Gaddi 'village' on either side of the Dhauladhar Mountains. It now boasts a concentration of NGOs, religious institutions and civil organisations unrivalled in any other Himalayan town of comparable size (Salmela 2014). Diverse populations of Gaddi tribals and Indian Gorkhas, Sindhi and Tibetan refugees, Rajasthani and rural migrants, international and domestic spiritual and leisure tourists, elite urban investors and middle-class weekend Delhiites, Kashmiri shopkeepers and Dalit porters - they are all perceived to radiate from and be socioeconomically enmeshed within the superstructure of diasporic ethno-commodification of Tibetan Buddhism. This patchwork of intensely incongruous cultural diversity localised in a small Himalayan township is often theorised as the epitome of a cosmopolitan, super-diverse, highly mobile and status-heterogeneous community in India.

Largely due to these associations, Dharamshala was selected in the 2015 Smart City Mission competition, a Modi-inspired development scheme intended to modernise 109 cities across India. From 2018-2022, approximately 150 million USD (1,000 crore) is being invested in Dharamshala (with COVID-19 delays) to realise its cosmopolitan potential with CCTV surveillance, free WIFI, improved transportation and digitalised consumer payment schemes. The Smart City was branded as 'Divine Dharamshala' - a spiritual hub that links development modernity with the ethno-commodification of Tibetan Buddhism. ${ }^{5}$ In 2019, the Himachal Pradesh government announced plans to construct a mega 'Buddha theme park' to further incentivise spiritual tourism to the home of the Dalai Lama. The proposed park would occupy nearly 40 acres in Khanyara, a Gaddi village in significant economic and cul- 
tural decline since the government banned open-pit slate quarrying due to ecological degradation.

I argue that cosmopolitanism in Dharamshala, both in theory and practice, is predicated on the instrumentalisation of Tibetan ethnicity and the felt exclusions of Gaddis. Gaddis are commonly described as a Scheduled Tribe (ST) due to their constitutional status and territorialisation in the Fifth Scheduled Reserved Area of Bharmaur; however, as discussed below, the 'tribe' is shifting towards multicultural inclusion and juridical recognition of Gaddi-identifying Scheduled Castes (SC) within the intersectional category of Scheduled Tribe Dalits (STD). After analysing the cosmopolitan exclusions in Dharamshala, I will reconsider Dharamshala through the Gaddi cultural imaginary. Most Gaddis live in Bharmaur, affectionately named Gadderan, which is constructed as the traditional Gaddi heartland through placemaking practices and discursive tropes that link authentic tribal identity to pastoralism, mobility and Shaivism. To the south of Gadderan, over the imposing Dhauladhars, migratory Gaddis took up residence in the southern spurs of what is now Kangra. Popularly called Jhandhar by Gaddis, these areas are associated with modernity and cosmopolitan aspiration due to the rapid development of tourist centres within the Gaddi orbit, especially Dharamshala. ${ }^{6}$ Gaddi identity does not exist in a tribal vacuum, territorially bounded in Gadderan, but is shaped by experiences in lowland ethnic borderlands like Dharamshala, which are shared with Tibetan neighbours.

\section{Marketplace Cosmopolitanism and Tibetan Ethno-commodification}

While cosmopolitanism in Dharamshala includes elite actors - international tourists, global citizens, scholars and entrepreneurs - analysing the divergent cosmopolitanisms of Tibetan refugees and Gaddi tribals focuses on non-elite, politically liminal subaltern actors. This focus is part of a recent turn in social theory towards hyphenated cosmopolitanisms - discrepant, vernacular, bottom-up, banal, working class, rooted and so on (Clifford 1997; Hannerz 2004; Appiah 2006; Beck and Sznaider 2006; Werbner 2008). Under the broad terminology of 'critical cosmopolitanism' is a methodological replacement of the universalising elite with everyday actors striving towards 'human openness that is processual, socially situated, aspirational, self- 
problematizing and aware of the incomplete and contested nature of any cosmopolitan claim' (Schiller and Irving 2015: 5). Scholars have found hyphenated cosmopolitanisms amongst itinerant street performers in Uttar Pradesh, public sector industrial workers in Chhattisgarh and Northeast tribal migrant labourers in Delhi, amongst others. Likewise, cosmopolitan instantiations in Dharamshala circle around non-elite actors, although I argue that Tibetan refugees live in broad structures of geopolitical goodwill, transnational patronage and discursive projections that can tip the balance of symbolic capital away from Gaddis in a marketplace privileging Tibetan ethno-commodification. To better understand the contestations and erasures within cosmopolitan orders, it is necessary to analyse how local conceptions and practices of cosmopolitanism are fashioned, whom they privilege and exclude, and how both Gaddis and Tibetans subjectively experience these in their situated contexts. I argue that while marketplace cosmopolitanism based on the ethnocommodification of Tibetan Buddhism coarsens interethnic sociality, we must also consider divergent conceptions of Gaddi cosmopolitanism rooted in cultural geographies, histories of transhumance and expanding conceptions of tribal ethnicity.

The difference is that many Tibetans operate within Dharamshala's superdiverse entrepreneurial community with the expectation of being (and being recognised by others as) cosmopolitan; consequently, they can generically draw from institutional support and structures of goodwill to develop intercultural competencies. Many Tibetans demonstrate cosmopolitan competencies in the sense of 'maneuvering more or less expertly with a particular system of meanings and meaningful forms' (Hannerz 1990: 239). In their analysis of transnational competence - those capacities that allow social actors to 'traverse and interlink levels (urban, rural, national, regional)' and recognise the 'permeable status of physical borders and intangible boundaries' - Peter Koehn and James Rosenau outline five competencies in interpersonal engagement: analytic, emotional, creative/imaginative, communicative and functional (Koehn and Rosenau 2010: 5-9). To a significant degree, Dharamshala Tibetans exhibit several of these competencies: managing multiplex identities in a transboundary context (emotional competence), drawing inspiration from a medley of cultural influences (imaginative competence) and learning English to facilitate crosscultural dialogue and mutual self-disclosure (communicative competence). However, these competencies can at once further a genuine 
worldview of openness to difference and be predicated on class privilege and benevolent Orientalism.

Meanwhile, divergent Gaddi cosmopolitanism is constructed around hybrid Chamba/Kangra identities, a tribe of castes undergoing ethnopolitical struggles for Dalit inclusion and yearly migrant labour cycles along the international tourist routes. These qualities are obscured in public discourses privileging the Tibetan/tourist dyad about what it means to construct experimental subjectivities and include radical cultural difference. It is important to emphasise the exclusions of Dharamshala cosmopolitanism as both a practiced set of competencies and an attendant cultural worldview. While the context of two hierarchically scaled subaltern groups has its own ethnographic contours, scholars are tuned into how local cosmopolitanism, in Darjeeling for example, can exclude subaltern migratory labourers and impose colonial-era racialised, gendered and class hierarchies (Sharma 2016). Moreover, Darjeeling cosmopolitanism, propelled by the ethnologic of state-recognised difference, has generated violent subnational agitations and tribalising strategies by Gorkha ethnic entrepreneurs that closely parallels the Gaddi mobilisation for ST status. ${ }^{7}$

Cosmopolitan exclusions in Dharamshala have outgrown their colonial origins and are inextricably linked with the Tibetan diaspora. Gaddis are often misrecognised, ignored or even portrayed as anachronistic tribal foils to cosmopolitan Tibetans. In his 1968 Asian Journal, the Kentucky Trappist monk Thomas Merton places the Dalai Lama at the centre of a mandala mapped onto the physical topography of Dharamshala; the dharmic universalisation of place sidelines the loud, scattered and benighted Gaddis (Johnson 2018: 254-257). In one passage, a Gaddi shepherd, unprovoked, defaces a devotional cairn (mani) seemingly to antagonise praying Tibetans. Merton's journal, perhaps the earliest recorded account, has gone on to inspire discursive representations of Dharamshala as a Tibetan spiritual hub with no Gaddi presence (see Chopra 2007).

These representations are not merely textual; the framing of Dharamshala as a Tibetan place directly impacts interethnic sociality ${ }^{8}$ It leads to toponymic contestation and the erasure of Gaddi cultural geographies; the Tibetan renaming of places and reimagining of localities according to Vajrayana cosmologies and through the nostalgia of exilic life have literally demonised Gaddis and eroded their place-based collective memories. Most Tibetans perpetuate a Shangri-La framework that elevates Buddhism as the foremost authenticating trope of Tibetan 
identity (Klieger 2002: 5). Living proximate to the Dalai Lama's residence is integral to claims of Tibetan authenticity. I have interviewed long-time Tibetan residents who have never heard of Gaddis or are openly disdainful of tribal culture - as if recognising Gaddis in the mandalic diversity decentres Buddhism or constructions of Tibetanness. Many international tourists express relief to be away from inscrutable Indians and amongst like-minded Tibetans with similarly cosmopolitan dispositions. Foreigners often experience Tibetan refugees as de facto cosmopolitans. Geographical dislocation, diasporic mobility, hybrid identity, flexible citizenship, intercultural dexterity, English fluency, foreign sponsorship, branded fashion, globe-trotting, cappuccino-sipping, social media-savvy - all these characteristics, apprehended through historically mediated representations, render Tibetans to the average international tourist as identifiably and obviously cosmopolitan.

It is common for scholars to merely gloss over Gaddis; the casual reader is left with a general impression that Dharamshala is a demographic mix of harmoniously cohabitating Tibetans and generic Indians. ${ }^{9}$ In her address to the US Senate Foreign Relations Committee Hearing on Tibet, Maura Moynihan (1997) described 'relations between the Tibetan refugees and their Indian hosts are as fine an example of peaceful co-existence of two distinct ethnic and cultural groups as can be found anywhere in the world'. This perspective is tempered by Atreyee Sen's (2015) analysis of 'crude cosmopolitanism' in Dharamshala; without mentioning Gaddis by name, she argues that Indians and Tibetans resolve intercommunal conflicts 'through a process of negotiation and acceptance' and the maintenance of a 'cordial cosmopolitan gloss' that facilitates (or at least does not impede) the tourist economy. Sen focuses on the circulation of discourses about cosmopolitan practices and aspirations of global identity amongst Tibetan refugees set against the backdrop of 'continuous human traffic, a cauldron of cultures and a melting pot of global ideas and ideologies brought along by travellers, tourists, academics, activists, journalists and worldwide followers of the spiritual leader' (Sen 2015: 88). Many Tibetans are obviously cosmopolitan, but so are Gaddis through a 'rooted tolerance, a worldview that was not the product of their own mobility, but of their community's ability to change itself by building relations with others travelling through their static world' (Sen 2015: 96). While I agree that some relatively sedentary Gaddis have developed cosmopolitan sensibilities by 'travelling-in-dwelling' (Clifford 1992), ${ }^{10}$ I argue that Gaddis 
also value mobility as both a discursive marker of tribal identity and a means of socioeconomic aspiration. As we will see, Gaddi vernacular cosmopolitanism draws from tribal histories of transhumance and cultural constructions of consumer modernity of Jhandhar.

Sen's analysis comports with the general feeling of marketplace tolerance, NGO do-gooderism and political activism that creates propinquity between tourists and Tibetans and overlooks Gaddis. ${ }^{11}$ It is common to overhear self-congratulatory banter in cafes about the cool cosmopolitan character of Dharamshala, where travellers, merchants and stateless refugees from varied backgrounds exchange overlapping conceptions of spirituality, politics and personal ethics. In fact, the intercultural competencies, self-reflexivity, moral relativism and aesthetic appreciation of difference are emblematic of cosmopolitan orientations (Werbner 2008). Many of these conversations centre on the exceptional character of Tibetans and Tibetan Buddhism; they are given experiential immediacy through monetary support in the varied forms of donations, sponsorship, volunteerism, meditation and dharma classes, Tibetan cooking, massage, thangka painting, language classes, dance classes, music classes, frequenting Tibetan establishments and purchasing Tibetan ethno-commodities. This café-culture cosmopolitanism, propelled by creating capital through engaging with difference and preserving cultural authenticity through the dialectic of 'exoticism and banalization' (Comaroff and Comaroff 2009: 142), almost entirely centres on Tibetans, playing out over cappuccinos in Tibetan-owned cafes with onlooking Gaddi cooks and wait staff.

Extending Sen's argument, Natalia Bloch (2018) claims that marketplace entrepreneurialism undergirds social cohesion and equally distributes cosmopolitan aspirations to all ethnic groups participating in the informal tourist economy. I find aspects of her conclusion need to be ethnographically qualified. First, Bloch's contention that all ethnic groups minimise cultural integration belies the overtly antiintegrationist ideologies of the Central Tibetan Administration (CTA), often couched as cultural preservation and the toponymic erasure of Gaddi cultural geographies by Tibetan naming practices. Gaddis expect Tibetans to culturally integrate after multiple generations of exiled life. As described earlier, the Tibetan posture of leapfrogging Indian culture (starting with Gaddi culture but including Hindi fluency and national citizenship) in pursuit of global cosmopolitan belonging sets the stage for Gaddi resentment. Second, and compounding this situation, Bloch assumes that all Dharamshala actors are equally en- 
dowed with intercultural skills and cosmopolitan dispositions necessary to maintain the tourism economy. However, fieldwork data highlights how Gaddis both feel and objectively are alienated from the cosmopolitan pageantries and even experience foreign patronage of Tibetans as collusive.

The main point of disagreement is about the ethnic neutrality of a marketplace cosmopolitanism based on the Dalai Lama as 'shared symbolic capital and source of (economic) well-being, which in turn helps to overcome the competition over land and cultural heritage ownership' (Bloch 2018: 49). Although Gaddis can materially benefit from the informal tourist economy, their everyday experiences engaging with Tibetan neighbours and international tourists affirm a sense of unbelonging. The ethno-commodification of Tibetan Buddhism may create a capitalist Wild West where Kashmiri merchants peddle thang$k a s$ as family heirlooms and Gaddis shopkeepers display Tibetan paraphernalia to attract tourists. Past these material superficialities, however, symbolic capital, transnational patronage, Tibetocentric forms of benevolent orientalism and intercultural competencies predominantly and transparently accrue to Tibetans over Gaddis. Rather than ameliorating ethnic communalism, I argue that the unequal distribution of symbolic capital to Tibetans has been, at least since the early 1990s, the primary source of Gaddi resentment. For many Gaddis, Tibetans are not merely vulnerable refugees, victims of Chinese atrocities, but also sophisticated entrepreneurs exchanging Tibetan Buddhism for financial patronage against the shadowy backdrop of geopolitical intrigue and media interests.

\section{Disjunctive Dharamshala}

Contrasting theories of Dharamshala's harmonious marketplace cosmopolitanism, some scholars and commentators have examined the simmering cultural disjunctures that can flare up into communalism. Transnational patronage is often attributed with creating actual wealth inequalities (Penny-Dimri 1994) or at least the perception of wealth inequalities due to Tibetan consumer behaviour and legal barriers to making land acquisitions (Prost 2006). Girija Saklani (1984: 378) was among the earliest scholars to note how Tibetan cultural exceptionalism impacts sociality, 'along with the understandable confusion among Indians who believe that refugees are beggars and should not be building new cement houses and driving around in four-wheel- 
drive jeeps'. Fieldwork conducted between 2010 and 2016 suggests that Gaddi resentments run deeper than wealth inequality; the erasure of cultural topographies and the exclusions of marketplace cosmopolitanism - a sense of material, geographical and discursive unbelonging - are intertwining factors. ${ }^{12}$ Keila Diehl (2002: 110) observed how Western tourists and many Dharamshala Tibetans have a shared disdain 'for the day-to-day realities of India-hardship, corruption, poverty, and filth - [which] is an important ingredient in the often-romantic collusion between these groups'.

As an American anthropologist, I had to engage in constant vigilance to research Tibetans without exacerbating Gaddi sensitivities about being overshadowed by their vogue neighbours. For example, at the onset of winter I bought a sweatshirt from the Students for a Free Tibet shop. Embossed on it were the words 'Pray for Tibet' and two hands folded in prayerful supplication. While wearing it, my Gaddi friends endlessly ribbed me. They treated my sweatshirt like a sartorial betrayal. I covered it up with a Gaddi kamrī, a woollen vest that has fallen somewhat out of local fashion, but even-handedness did not automatically assuage Gaddi concerns. I was often caught 'red-handed' with Tibetan friends or strolling out of the Namgyal Monastery. Tibetans, for their part, have their own expectations towards foreign researchers (Henrion-Dourcy 2014) and occasionally express disappointment that I bother researching Gaddi tribal politics. For many Tibetans, cosmopolitan sensibilities extend only to the border of Gaddi life - this includes research paradigms. Gaddis generically represent the fringe of Indian society, the backwardness against which cosmopolitan values are measured; placed in the broader South Asian context, Gaddis become part-and-parcel with the negative framing of Indians by Tibetan merchants who emphasise Indian baseness as an ostensible basis for displaced fears of cultural assimilation (Lau 2009). ${ }^{13}$

Dharamshala seems to be perpetually gesturing outside itself. The name 'Dharamshala' is suggestive of its Sanskritic etymology as a temporal resting place, a place not firmly rooted. Many Gaddis, who discursively frame themselves as pastoral 'roamers' (ghumantu) and 'six-monthers' (chahmahine), split their time between seasonally mild winters in low-lying villages around Dharamshala and summers in their ancestral homes in Chamba. Tourism cycles throughout the year, peaking in the pre- and post-monsoon months, and consumer desires, from handicrafts to spiritual and leisure experiences, are met by a range of itinerant Kashmiri merchants and porters, Punjabi busi- 
nessmen and low-skilled labourers from both remote Gaddi villages and further afield, from Chhattisgarh, Bihar and Rajasthan. From October until early March, many Tibetans leave Dharamshala for seasonal 'sweater markets' in dozens of Indian cities, where they hawk clothing bought wholesale in Ludhiana. Dwindling numbers of Tibetan new arrivals matriculate into Tibetan schools and NGOs in Dharamshala before repatriating, relocating abroad or shifting to another settlement in India. For many, Dharamshala is less a permanent home than a contested zone of temporality.

Despite many decades of tight-spaced cohabitation, there is a notable paucity of religious syncretism and cultural integration. Tibetans rarely attend Gaddi communal rituals, do not consult with local Gaddi traditional faith healers and are largely unaware of how Gaddi divinities factor into local spiritual geographies. However, some Tibetans feel propinquity with Hindu snake spirits and may worship at Indrunag Temple in Bhagsu, a Gaddi village on the broader temple tourist circuit, or in Lower Dharamshala at the non-Gaddi Rainitaal Nag Mandir. While conducting fieldwork with Gaddi shepherds along the Souli Khad rivulet dividing McLeod Ganj from the Hali slate-quarrying village of Thathri to the east, Tibetan herbalists came on several occasions to buy the milk of auspiciously white-coloured goats as a compound for traditional medicine. ${ }^{14}$ This has led to some degree of informal networking. Community outreach programming of the Namgyal Monastery often includes prominent Gaddis, such as members of the Indo-Tibetan Friendship Association, local village leaders and the original Gaddi inhabitants of McLeod Ganj. Likewise, Gaddi employees have enrolled a handful of children at the Tibetan Children's Village school in Naddi. Tong-Len, a Tibetan-run NGO, is promoting the universalisation of Tibetan Buddhist ethics across Dharamshala, including at Hindi-medium government schools in predominantly Gaddi villages.

Gaddis, for their part, generally steer away from popular manifestations of Tibetan Buddhism and the support of Tibetan political autonomy. Most Gaddi porters and flaneurs vacate McLeod Ganj's main square during Tibetan rallies against Chinese suppression. Some Gaddi youth wear recycled pro-Tibet $\mathrm{t}$-shirts but are unaware of its meaning and unsupportive of its ideological messaging; more business-savvy Gaddis wear pro-Tibet clothing to elicit sympathy from international tourists and lure them into their shops. A Gaddi hair stylist half-joked that the Dalai Lama, whose portrait hangs reverentially above the re- 
clining barber chairs, generates more business than Laxmi, the Hindu goddess of wealth. ${ }^{15}$

Gaddi ambivalence about Tibetan Buddhism is present in oral narratives of first contact, when bedraggled Tibetan refugees set up makeshift encampments in Dharamshala in the early 1960s. Gaddi elders recounted early rumours about Tibetan cannibalism and anxieties about shape-shifting, red-robed Tibetan monk-monsters. ${ }^{16}$ Since the 1990s international patronage boom, many Gaddis consider Tibetan Buddhism as a commodity trademarked by refugees and unequally distributing vast sums of capital. Such resentments manifest in innocuous Gaddi joking; for example, that the Tibetan mantra om mani padme hüm is actually 'Oh Money Pay Me Soon'. They are deepened by casual observances of iPhone-using, cappuccino-sipping monks and village rumours surrounding the indulgences of the $17^{\text {th }}$ Karmapa. Conversely, I have heard about Gaddis seeking out faith healing from Khandro La, the Tibetan medium for the Tenma Oracle who resides in Dharamshala. At least one Gaddi Brahmin family priest (kul purohit) in Naddi has adopted a Tibetan monk as his 'Guru-ji' since childhood leading to interreligious dialogue (Christopher 2020). Overall, the ethno-commodification of Tibetan Buddhism, both real and imagined, manifests in a sense of Gaddi psychosocial displacement amidst a home they feel they are losing and an economic system colluding against them.

\section{Divergent Gaddi Cosmopolitanisms}

Despite cosmopolitan exclusions in the marketplace of ethnocommodified Tibetan Buddhism, Gaddis have forged an alternate, grounded cosmopolitanism based on cultural skills fostered through pastoral transhumance, seasonal labour migration corresponding with foreign tourists and ongoing ethnopolitical redefinition of what it means to be tribal itself. Although pastoral transhumance has declined (Phillimore 2014), fantasies of a peripatetic lifestyle of the Himalayan shepherd are in vogue. Of course, Gaddis are not clamouring to trade in sedentary employment in the tourism or civil service sector for the hardscrabble migratory cycle between Chamba and Kangra. Gaddi youth are, however, celebrating a lifestyle of itinerancy and indeterminacy on social media platforms using the hashtag \#radkaat (rarkāt - ' wanderer'. The Kangri cartoonist @BaankiBitti published a popular image of a carefree shepherd among his flock at pasture with rarkāt emblazoned across the Himalayan sky. Under the hashtag, mountain youth express a longing to resist social conventions, escape urban materialism and 
journey to authentic self-discovery in a Thoreauvian exploration of nature ${ }^{17}$ Previously, the high-Hindi word 'ghumakkar' conveyed these aspirations among a minority contingent of Gaddi mountain guides and café workers hanging out with hash-smoking international tourists. Now, propelled by social media and a bit of disenchantment with neoliberalism, mainstream Gaddi youth are reclaiming a wandering lifestyle in their own dialect and expressing localised conceptions of cosmopolitanism divergent from the Tibetan model. In this section, I briefly sketch the roots of Gaddi cosmopolitanism, and how this manifests in labour migration and ethnopolitical redefinition.

As described earlier, most Gaddis live in Bharmaur, a tribally reserved area in Chamba District that roughly maps onto the boundaries of Gadderan, the emic nomenclature for the Gaddi homeland. A Gaddi contingent migrated into the southern foothills of the Dhauladhars, which at the time was part of the Punjab and called Jhandhar. Scholars have explored how mobile Gaddi pastoralists exhibited cultural dexterity negotiating taxation regimes and establishing economic interdependence with caste-agriculturalists during the colonial period (Singh 2019). ${ }^{18}$ As Gaddi shepherds traversed and settled in culturally distinct regions, Gaddi dialect became inflected with Punjabi and Gaddi ritual semantically shifted towards emulating local caste configurations (Sharma 2015). Gaddi shepherds developed formal and informal competencies accessing grazing resources and maintaining traditional livelihoods in the face of ecological imperialism (Axelby 2007). Many Jhandhar Gaddis self-identify as former roamers and maintain complex hybrid identities as ancestrally belonging to Gadderan while culturally and temperamentally different from Chamba Gaddis. Although it is politically expedient that recipients of ST benefits are considered (and sometimes consider themselves) as country bumpkins, this stereotype is belied by their cosmopolitan lifestyles and the global interconnectedness of Kangra. ${ }^{19}$

For many Gaddis, Jhandhar is semantic shorthand for modernity, a place of new possibilities. A Gaddi folksong about a departing Bharmauri husband encapsulates this connotation:

Wife: You are going to Jhandhar my love (bhora). What will you bring for me?

Husband: I will bring coconuts; I will bring dates.

Wife: You are going to the plains my love. What will you bring for me?

Husband: I will bring a piece of soap, a vial of perfume and a handkerchief.

Jhandhar is now famous for much more than soap and tropical fruit. Phillimore (2014) highlights several factors that contribute to its unique 
prosperity: favourable rainfall for agriculture, alluring safety for migratory Punjabis, an expanding middle class and increasing migrant labourer force for road construction and domestic service, army bases and recruitment centres, international patronage flowing to Tibetan refugees and increased tourism for paragliding. I would add new allurements for domestic tourists, such as the HPCA international cricket stadium and the designation of Dharamshala as a Smart City. Lower Dharamshala recently birthed its first modern mall replete with a food court and multiplex movie theatre screening western films. The 2010 implementation of the rural tourism scheme 'The Story of Every Village' (har gānv kì kahānī) has increased flow to several Gaddi villages. Commercial flights between Delhi and Gaggal provide new connectivity, and a detailed project report has been submitted to link Kangra and Chamba via a motorable tunnel. The matrix of colonial-era government offices and libraries in Lower Dharamshala continue to attract 20-something Gaddis with aspirations for civil service.

The perceived modernity of Jhandhar, radiating from Dharamshala, ${ }^{20}$ shapes how Gaddis construct 'modern' tribal identities, preserve cultural uniqueness and mobilise for ethnopolitical inclusion. When Gaddis seek out cosmopolitan experiences - whether leisure travel, employment opportunity, language proficiency or an enlarged sense of self through adventurous engagement with the ethnic Other - they keep this geographical framework in mind.

This is evident in labour migration. Upper Dharamshala attracts Gaddis from nearby rural villages whose livelihoods are circumscribed by scratch farming and rural employment schemes. ${ }^{21}$ When the government banned open-pit slate quarrying in Thathri and Khanyara, many SC Gaddis (predominantly Dhogri and Hali) shifted to Upper Dharamshala. One family sold forest-foraged fiddlehead fern (fonfaru) in newspaper packets on TIPA Road. One afternoon, the 14-year-old son, having seen a portrait of the Dalai Lama for the first time, asked me if he was Nepali royalty. Two brothers set up a roadside meat stall; one dated a Gorkha and the other studied Hebrew to communicate with Israeli backpackers. McLeod Ganj is both a recognisably Gaddi place and a global hub of possible self-redefinition, a modern capitalist town wholly dissimilar from not only their nearby natal villages but also all Kangra villages (with the scaled-down exception of Bir).

These dynamics are even more evident amongst SC Gaddi young men of the Badi caste who have eschewed village scratch farming (partly due to invasive foreign plants and monkey infestations) and shifted 
to Upper Dharamshala to take up tourism-related service jobs. Since at least the mid-1960s, the remote northwestern corner of Dharamshala has been tied to the Tibetans in Dharamshala through the sale of milk. Gaddis from Kareri and Badis from Khari Bahi strapped metal pots containing $20 \mathrm{~kg}$ of milk on their backs and walked several hours by footpath. They distributed milk to predominantly Tibetan customers living near the Tsuglagkhang, spent the day in the market and returned home by foot before nightfall.

While the ready availability of packet milk has nearly eliminated this source of income, Badi men have migrated in huge numbers to Upper Dharamshala. Among all SC Gaddis, Badis are the most likely to work under Tibetans during the seasonal sweater market, in places as far-flung as Hampi, Varanasi and Madurai. The impact of seasonal tourism on Badis cannot be overstated. It structures their sensibilities and provides an avenue for redefining what it means to be nomadic in modern India. With villages like Naddi, Dal, Bhagsu and Dharamkot crammed in the summer and vacant during winter, hundreds of Kangra Gaddis shift to Goa between November and April. Given their small demographics, Badis are vastly overrepresented among these Gaddi migrants. Some spend the entire year following tourists, from Upper Dharamshala to Goa to Manali or Leh, and return home for two weeks out of the year. Attention to this cohort of SC Gaddis highlights how Himalayan tribals (and tribal aspirants) seek redefinition in the larger world and, ultimately, back at home (McDuie-Ra 2012).

I conducted two months of fieldwork with Badi migrant workers in Goa. Interestingly, the effects of working in tiny Goa, not far off the equator, were mostly to reinforce the tribal subjectivities of Badis through social media networking and interpersonal interactions with fellow Gaddi Rajput workers. Many recoiled from the exotic beach culture and retreated into the familiar lap of Himalayan tribal belonging. Such effects depended on work location (beachfront versus roadside; hippie enclave versus upscale resort), personal sensibilities, English proficiency, social networking skills and the vagaries of the work itself. For example, anxiety about beef-eating local Christians and Muslims obviated traditional concerns about tribal caste hierarchy. Gaddi cooks living near the Karnataka border described how their Christian boss learned the hard way to keep the restaurant kitchen beef-free. After eating beef forcibly prepared by Gaddi cooks in the restaurant kitchen, his body became infected with spots (khujali). The Gaddi workers attributed his sickness to the anger of a nearby snake spirit, who 
makes a ruckus (hangāmā) whenever Gaddi cooks prepare beef against their will. Whether expressed through the idiom of snake protection or general unease about Christians and Muslims, the spectre of beefeating shifts traditional purity considerations once relegated to Gaddi low-status groups and their 'polluting' forms of labour. The uniformity of Gaddi suspicion about alleged beef-eating religious minorities becomes an important site of intercaste solidarity, contrasting the purity of Himalayan Shaivism, regardless of caste position, with the barbarism of Goan diets. This mentality also reverses the perceived 'barbarism' of Gaddi sheep sacrifice, which looks benign set against the obvious sinfulness of cow slaughter. ${ }^{22}$ Moreover, this problematic allows Gaddis to assert their independence and occasionally reject employment at restaurants serving beef; Gaddis proudly recite these rejections as moments of agency amidst a Goan experience in which decisions become increasingly circumscribed and migrant lives are narrowed by exacting bosses, long hours, cultural unfamiliarity and the need to send home remittances.

Much more remains to be said about Gaddi migrants working in the informal tourist economy in Goa and throughout India. Suffice to say that some Gaddis migrate for novelty, others for personal transformation; some save their salaries over several seasons and establish businesses in Dharamshala, others send home remittances to support impoverished family members; some are frugal, limiting expenditures to toiletries and phone recharge bills, others blow through their salaries partying with tourists and adopting expat lifestyles. Nearly all follow the same route from interior villages to Upper Dharamshala to Goan restaurant. Living in tight quarters, SC and ST Gaddis mix more freely than at home in Himachal: sleeping on adjacent mattresses, toking from the same spliffs and sharing common plates - intimate expressions that were once fault lines for tribal casteism. Some cultivate an enlarged sense of self through new forms of intimacy, consumption and experience, while nearly all further collapse caste ideologies separating SC and ST Gaddis in Himachal. 'Goa allows us to act as we like (apni marzi)', a Gaddi Rajput explained. 'The caste problem (chakkar) in Gaddi villages - 'Who are you? (tu quon?) - it's a disease that doesn't survive in this hot weather'.

Gaddi ethnopolitical movements provide the cure for the disease of tribal casteism and is an ethnographically remarkable instance of tribal cosmopolitanism. The effort underway to reimagine the Gaddi tribe as a community of unequal castes - ranging from Bhatt Brahmins 
and Gaddi Rajputs to five Scheduled Castes - is indebted to shifting attitudes about multicultural inclusion and legal protections for the socially marginalised. These shifts were instigated in the early 2000s when, based on an ethnological survey of Dharamshala and adjoining villages, high-caste Kangra Gaddis were granted the political designation of ST and, as such, rights-availing as a historically-marginalised community.

Putting aside how reservation politics pushes tribal aspirants into paradoxically aspiring for modernity by performing primitiveness, I want to emphasise how political reclassification did not extend to five SC castes which self-identify as Gaddi. They conceive of Gaddi as a community (samudāy) bracketing a Herderian shared identity - dialect, dress, cuisine, ritual and culture - that extends across the four social classifications (varna) and includes seven castes (jäti). Their differences, they contend, are the product of tribal casteism and colonial state ethnological paradigms that fail to recognise an intersectional Dalit identity within tribal formations. The psychic harms of misrecognition have led to grassroots appeals for the constitutional recognition of the intersectional identity 'Scheduled Tribe Dalit' (Christopher 2020b) and religious conversion (Christopher forthcoming). Many high-caste Gaddis, especially from younger age cohorts and living in Dharamshala, are accepting of a more inclusive tribal identity that recognises the historical subordination of Dalits and authentically aspires to a broader, caste-inclusive community. While these shifts in ethnic subjectivity are unevenly spread across villages in Gadderan and Jhandhar, certainly Dharamshala is a hub for grassroots activism and political protest. ${ }^{23}$

This involves many of the features of cosmopolitanism outlined by Ulf Hannerz (1990): an openness to difference, a dexterity manoeuvring within cultural systems and a contrasting of differences (in this case, caste differences subsumed within a shared Gaddi tribal community). These competencies are honed in Dharamshala, in the ethnic borderlands shared with Tibetans, where exclusionary forms of refugee cosmopolitanism shapes tribal subjectivity. Although Gaddis rarely network with Tibetans on shared problems of cultural preservation or state recognition, Gaddi ethnic entrepreneurs strategise for raising awareness based on the more prominent Tibetan model.

\section{Conclusion}

I have argued that cosmopolitanism is deployed as symbolic capital structuring social inequalities between Tibetan refugees and Gaddi 
tribals. Although cosmopolitanism implies global citizenship and philosophical openness to difference, at the ethnographic level it can lead to local social exclusions and feelings of ethnic resentment and geographical alienation. Recognising this does not demonise one community over the other: both Tibetans and Gaddis are vulnerable communities facing varying degrees of state surveillance, ethnic stereotyping from mainstream Indians and insecurity about cultural loss. Whereas Gaddis have historically been more prone to violent outbursts and physical intimidations against Tibetans, Tibetans have exerted significant socioeconomic pressure over Gaddis through ethnic boycotting and ownership of several civic organisations that indelibly shape Dharamshala. These contextual power dynamics should not, however, overlook the reality that Gaddis and Tibetans are not equal service providers in an informal tourist economy; the expectation of cosmopolitanism and opportunities for intercultural competencies heavily favour Tibetans in a marketplace predicated on Tibetan Buddhism. Although Gaddi divinities live in local temples and household shrines dotted throughout Dharamshala, the Dalai Lama and Tibetan Buddhism make it 'Divine'. The Mind \& Life Conference is often hosted in Dharamshala, where scholars abstract general principles of human flourishing from the intersection of scientific empiricism and contemplative Buddhist wisdom. Such discussions engage Gaddis only obliquely; for example, when murals of 'secular ethics' for universal wellbeing derived from the 2018 conference are painted at Gaddi-dominated rural government schools. Should the Asian Development Fund construct a mega Buddha theme park for more than 25 million USD, Dharamshala will become permanently branded as a Buddhist tourist destination, further propping up the value of Tibetan ethno-commodification.

However, as the Dalai Lama ages, Tibetan on-migration increases and international tourists are dwarfed by domestic tourists with radically different travel priorities, Gaddi cosmopolitan aspiration may have more opportunities to become mainstream. After all, both Tibetans and Gaddis already express 'subaltern cosmopolitanism' as a mode of synthesising information across multiple boundaries that critiques established norms and unearths power relations within claims of depoliticised difference (Gidwani 2006); changing tourism demographics may shift the ideological underpinnings of marketplace cosmopolitanism and bring more equal visibility to both communities. For example, two Gaddi women recently performed parts of the Vagina Monologues in Gaddi dialect for d.r.i.f.t., a multicultural, multilingual 
theatre group that promotes community solidarity and cosmopolitan values. ${ }^{24}$ The construction of hostels (most notably Zostel) on rented Gaddi properties in Dharamkot is creating novel spaces for intercultural dialogue between Gaddis and mainstream Indian youth - who are as likely to have romanticised stereotypes of Shiva-worshipping tribals as contemplative Tibetan Buddhists. Alternatively, both Gaddis and Tibetans may be sidelined by runaway extractive capitalism, symbolised by the 2019 Global Investors' Meet in Lower Dharamshala and construction of the five-star Hyatt Regency hotel below the Tushita Tibetan Buddhist Meditation Centre. In an entrepreneurial marketplace fuelled by outside business interests and shifting consumer desires, new ethno-commodities and cosmopolitan ideologies may gain unexpected currency.

STEPHEN CHRISTOPHER is a lecturer at Tokyo Metropolitan University. He is the Himalayas editor at the Database of Religious History at the University of British Columbia. Email: Stephen.Christopher110@gmail.com.

\section{NOTES}

1 Tibetans are clustered in McLeod Ganj, sometimes called 'Upper Dharamshala', 'Dharamshala', 'Dhasa' or nicknamed 'Little Lhasa'. However, the Gaddi-Tibetan interface includes adjacent villages such as Dusalni, Jogiwara, Naddi, Bhagsu, Fatehpur and Gamru. In this article, I opt for an inclusive 'Dharamshala' to highlight the multiple sites of interaction, and 'McLeod Ganj' when specifying the dynamics of Upper Dharamshala.

2 This article is based on ongoing research conducted since 2013. The research was supported by a Fulbright-Nehru Doctoral Research Fellowship, a Bharati Memorial Grant, a Roscoe-Martin Grant, Syracuse University and a Japanese Society for the Promotion of Science (JSPS) Postdoctoral Fellowship at Kyoto University.

3 Sen (2015) describes the 'cordial cosmopolitan gloss' and 'crude cosmopolitanism' that resolves ethnic resentments and underpins the tourist economy; Bloch (2020) analyses how tourism service providers develop intercultural competencies on the way to becoming local entrepreneurs in a marketplace cosmopolitanism.

4 Dharamshala, a British cantonment advertised as the wholesome alternative to debauched Shimla, was annexed to further colonial designs on the northwest frontier (Kennedy 1996: 13).

5 Althogh 'Divine Dharamshala' is not nearly as iconic as Shimla's tag 'Queen of the Hill Stations', it is circulating on various tourist websites and social media platforms. The Dalai Lama was even labelled a 'brand ambassador' by city planners. In some contexts, the 'divinity' of Dharamshala broadly includes the Seven Sisters pilgrimage, Hindu yoga and herbal treatments and Himalayan Shaivism. The significance of Gaddi spirituality in Dharamshala, which links Kangra to Chamba through snake propitiation, is overlooked in discursive representations of divinity. 
6 Jhandhar includes Gaddi-dominated low-lying villages on the southern spurs of the Dhauladhars, stretching from around Dharamshala to the west, Bir to the east, and extending south to Maharana Pratap Sagar and Ganehr. Occasionally it designates anywhere south of Gadderan, the Gaddi homeland. This article opts for the restricted use of Jhandhar as Gaddi habitations on the southern spurs of the Dhauladhars and spreading into the Kangra plains.

7 Both Gorkha and Gaddi ethnic associations advocate for recognition of tribal Dalits (Middleton 2016: 98).

8 Without relitigating the debate over whether western representations imprison Tibetan subjectivities in looping cultural mimicry and hybridisation, I want to emphasise how positive stereotypes shape Tibetanisation of place and Tibetocentric conceptions of cosmopolitanism. The historical fashioning of dichotomous and often contradictory stereotypes about Tibetans have been largely flattened into the positive stereotypes of benevolent orientalism and accrue to Tibetans with Gaddis as tribal foils.

9 For example, in his book on the 'global journey' of the Dalai Lama, Pico Iyer (2008: 148) describes the "Naddi tribe" and he never corrected this oversight in subsequent editions.

10 Satellite villages of McLeod Ganj have transformed from Gaddi mud homes to multistory cement structures rented out to mobile Tibetans and tourists. While high-caste ST Gaddis had an early advantage, financing renovations with consolidated flock wealth, tourists have recently spilled into SC Gaddi villages, injecting marginal Gaddi castes with economic resources and accessible cosmopolitanism. For example, a Gaddi Hali learned chess from a German businessman and trained his daughter, who is the only female representing Himachal Pradesh in all-India competitive matches. The German bankrolled a suite above their home, an ostentatious addition, which will legally revert to the Hali family after his death. This financial windfall has transformed the social position of the low-caste family, owners of a corrugated-iron tea stall illegally encroached on government property. Between an inter-caste marriage, a chess champion and unusually intimate relationships with a Hindi-speaking Tibetan monk and a Gaddi Brahmin priest, the Hali family exemplifies a rooted cosmopolitan sensibility.

11 Kashmiri merchants and non-Gaddi migrant day labourers are similarly overlooked for vastly different reasons. The former remain embroiled in a legal dispute with the CTA about the appropriation of a historic masjid and perform namāz on the rubbish-strewn grassy embankment below the bus station; the latter were removed from their slum dwelling in Charan Khad to make Dharamshala fit the objectives of the Smart City scheme.

12. While I agree with Bloch (2019: 4), that Gaddi perplexity about perceived Tibetan wealth is indicative of a reactionary mentality to consign refugees to ideal victimhood' and expectations of poverty, closer examination suggests that social contestations about cultural and toponymic recognition outstrip the host/ victim dichotomy.

13. An increasingly frequent exception is the temporary social affinity of Tibetans, Gaddis and all Dharamshala residents when pitted against rowdy Indian tourists, especially after a cricket match. Criticising Indian weekend tourists for being drunk, boisterous, polluting wastrels - epitomised by 17-seater Tempos snarled in traffic - creates a temporary groupness that has sometimes pitted Gaddis and Tibetans on the same side of physical altercations. 
14 This included both individual Tibetans and employees of Men-Tsee-Khang Tibetan Medical and Astro Institute.

15 Economic pragmatism does not account for all expressions of intergroup solidarity. For example, Gaddi women who provide birthing assistance to expectant Tibetan mothers (Sen 2015); five Gaddi-Tibetan intermarriages in the face of conservative endogamous expectations from both communities; an aspiring Gaddi writer publishing a heartfelt poem about Tibetan displacement; or a Gaddi taxi driver placing himself in danger to drive a COVID-19 infected Tibetan to the hospital.

16 Gaddi elders describe being hoodwinked by worldly-wise Tibetan merchants: exchanging Kapoor-encrusted heirloom necklaces for asafetida (hing), a digestive powder added to savoury foods. Some Settler Tibetans negatively coded Gaddis as ancestors of slaves to the demon-king Lutsen in the oral epic Ling Gesar, which may have further alienated Gaddis from Vajrayana Buddhism (Johnson 2018).

17 Examples of \#radkaat on popular Kangri accounts: 'Leave city, leave reality; enter forest, enter fantasy'; 'Birds have wings, soul have dreams'; 'Don't let limits define $u$ cause $u$ are limitless!'; ' I'm not lost, just exploring'.

18 Compounding this perception are colonial stereotypes of Gaddi shyness and the still-used 1965 Lokur Committee's delineation of backwards tribal qualities.

19 On the interconnectedness of Kangra and cosmopolitanism amongst nonGaddi Kangris, see Narayan (2007).

20 Palampur, boasting a sizable university and middle class, is a burgeoning city for modern aspirations; Bir, a small town comprising 'local' Gaddis and Tibetan refugees within an informal tourist economy catering to international adventure and spiritual tourists, has similar connotations with Dharamshala.

21 Even rural employment schemes (MNREGA) have disappeared in nine Gaddi villages absorbed into the Dharamshala Municipal Corporation.

22 Reflected in the Himachal Pradesh High Court's ban (and eventual reversal) of animal sacrifice, primarily directed at the spectacle of buffalo slaughter in Kullu but nervously received by Gaddis.

23 Several prominent advocates for Dalit inclusion in the Gaddi ST quota live in Dharamshala. The Gaddi student-led Kailash Association is based in Lower Dharamshala. Legal petitions for constitutional inclusion of STDs are often submitted in Dharamshala's Vidhan Sabha constituency. Caste emendations for Gaddi Aryas are done through the Revenue Record Office in Dharamshala.

24 The organisation, founded by a South Indian indebted to Tibetans because her parents sought out cancer treatment at Men-Tsee-Khang, has shifted the target audience from primarily Tibetans and tourists to include Gaddis and Kangris.

\section{REFERENCES}

Appiah, Kwame Anthony 2006. The Ethics of Identity. Princeton: Princeton University Press.

Axelby, Richard 2007. “"It Takes Two Hands to Clap”: How Gaddi Shepherds in the Indian Himalayas Negotiate Access to Grazing'. Journal of Agrarian Change 7 (1): 35-75.

Beck, Ulrich, and Natan Sznaider 2006. 'A Literature on Cosmopolitanism: An Overview'. British Journal of Sociology 57 (1): 153-164. 
Bentz, Anne-Sophie 2012. 'Being a Tibetan Refugee in India'. Refugee Survey Quarterly 31 (1): 80-107.

Bloch, Natalia 2018. 'Making a Community Embedded in Mobility: Refugees, Migrants, and Tourists in Dharamshala (India)'. Transfers 8 (3): 36-54.

Bloch, Natalia 2019. 'Refugees as Donors: "Rich" Tibetan Refugees, Evicted Indian Slum Dwellers and a Smart City'. Journal of Refugee Studies, https://doi.org/10.1093/jrs/fez106.

Bloch, Natalia 2020. 'Beyond a sedentary Other and a mobile tourist: Transgressing mobility categories in the informal tourism sector in India'. Critique of Anthropology 40 (2): 218-237.

Chopra, Swati 2007. Dharamsala Diaries. New Delhi: Penguin Books.

Christopher, Stephen 2020a. 'The Interdependence and Exclusions of Tibetan and Tribal Identities in Dharamshala'. (In Japanese translation). Journal of Social Science and Humanities, Tokyo Metropolitan University 516 (2): 115-140.

Christopher, Stephen 2020b. "'Scheduled Tribal Dalit" and the Emergence of a Contested Intersectional Identity'. Journal of Social Inclusion Studies. Delhi: Indian Institute of Dalit Studies 6(1): 1-17.

Christopher, Stephen forthcoming. 'Critique of the Spirit: Gaddi Spiritual Torment and Aspirational Hermeneutics'. In R.K. Kale and S. Acharya (eds.) Inclusion and Access in the Land of Unequal Opportunities: Mapping Identity-induced Marginalisation in India. Delhi: Springer.

Clifford, James 1992. 'Traveling Cultures'. In L. Grossberg (ed.) Cultural Studies. London: Routledge, pp. 96-116.

Clifford, James 1997. Routes: Travel and Translation in the Late Twentieth Century. Cambridge: Harvard University Press.

Comaroff, Jean, and John Comaroff 2009. Ethnicity, Inc. Chicago: University of Chicago Press.

Diehl, Keila 2002. Echoes from Dharamshala: Music in the Life of a Tibetan Refugee Community. Berkeley: University of California Press.

Gidwani, Vinay K 2006. 'Subaltern Cosmopolitanism as Politics'. Antipode 38 (1): 7-21.

Hannerz, Ulf 1990. 'Cosmopolitans and Locals in World Culture'. Theory, Culture, and Society 7 (2-3): 237-252.

Hannerz, Ulf 2004. 'Cosmopolitanism'. In D. Nugent and J. Vincent (eds.) A Companion to the Anthropology of Politics. Oxford: Blackwell, pp. 69-85.

Henrion-Dourcy, Isabelle 2014. 'Easier in Exile? Comparative Observations on Doing Research among Tibetans in Lhasa and 
Dharamsala.' In S. Turner (ed.) Red Stamps and Gold Stars: Fieldwork Dilemmas in Upland Socialist Asia. Vancouver: University of British Columbia Press, pp. 201-219.

Iyer, Pico 2008. The Open Road: The Global Journey of the Fourteenth Dalai Lama. New York: Vintage.

Johnson, Steven Christopher 2018. Tribal Margins: Dalit Belonging and State Recognition in the Western Himalayas. Ph.D. dissertation, Syracuse University.

Kennedy, Dane Keith 1996. The Magic Mountains: Hill Stations and the British Raj. California: University of California Press.

Klieger, Christiaan 2002. 'Engendering Tibet: Power, Self and Change in the Diaspora'. In C. Klieger (ed.) Tibet, Self, and the Tibetan Diaspora: Voices of Difference. Proceedings of the Ninth Seminar of the International Association for Tibetan Studies. Leiden: Brill, pp. 139-154.

Koehn, Peter H. and James Rosenau 2010. Transnational Competence: Empowering Curriculums for Horizon-rising Challenges. New York: Routledge Press.

Lau, Timm 2009. 'Tibetan Fears and Indian Foes: Fears of Cultural Extinction and Antagonism as Discursive Strategy'. Vis-a-vis: Explorations in Anthropology 9 (1): 81-90.

McDuie-Ra, Duncan 2012. Northeast Migrants in Delhi: Race, Refuge and Retail. Netherlands: Amsterdam University Press.

McGranahan, Carole 2016. 'Refusal and the Gift of Citizenship'. Cultural Anthropology 31 (3): 334-341.

Middleton, Townsend 2016. The Demands of Recognition: State Anthropology and Ethnopolitics in Darjeeling. Stanford: Stanford University Press.

Moynihan, Maura 1997. US Senate Foreign Relations Committee Hearing on Tibet.

Narayan, Kirin 2007. 'Moving Stories: Beyond the Local in Ethnography and Fiction'. In K. Robinson (ed.) Asian and Pacific Cosmopolitans. London: Palgrave Macmillan, pp. 60-76.

Penny-Dimri, Sandra 1994. 'Conflict Amongst the Tibetans and Indians of North India: Communal Violence and Welfare Dollars'. Australian Journal of Anthropology 5 (3): 280-293.

Phillimore, Peter 2014. "“That Used to be a Famous Village": Shedding the Past in Rural North India'. Modern South Asia 48 (1): 159-187.

Prost, Audrey 2006. "The Problem with "Rich Refugees": Sponsorship, Capital, and the Informal Economy of Tibetan Refugees'. Modern Asian Studies 40 (1): 233-253. 
Saklani, Girija 1984. The Uprooted Tibetans in India: A Sociological Study of Continuity and Change. New Delhi: Cosmo Publications.

Salmela, Noora 2014. 'Indian NGOs and their Role of Networking'. In R.B. Singh and R. Hietala (eds.) Livelihood Security in Northwestern Himalaya: Case Studies from Changing Socio-economic Environments in Himachal Pradesh, India. Tokyo: Springer, pp. 173-188.

Schiller, Nina Glick, and Andrew Irving 2015. 'What's in a Word? What's in a Question?' In N. G. Schiller and A. Irving (eds.) Whose Cosmopolitanism?: Critical Perspectives, Relationalities and Discontents. London: Berghahn Books, pp. 1-26.

Sen, Atreyee 2015. “'It's Cool to Be Cosmo": Tibetan Refugees, Indian Hosts, Richard Gere and "Crude Cosmopolitanism" in Dharamshala'. In N. G. Schiller and A. Irving (eds.) Whose Cosmopolitanism?: Critical Perspectives, Relationalities and Discontents. London: Berghahn Books, pp. 87-102.

Sharma, Jayeeta 2016. 'Producing Himalayan Darjeeling: Mobile People and Mountain Encounters'. Himalaya: The Journal of the Association for Nepal and Himalayan Studies 35 (2): 87-101.

Sharma, Mahesh 2015. 'Ritual, Performance, and Transmission: The Gaddi Shepherds of Himachal Himalayas'. Oral Tradition 29 (2): 271290.

Singh, Chetan 2019. Himalayan Histories: Economy, Polity, Religious Traditions. New York: SUNY Press.

Werbner, Pnina 2008. 'Introduction: Towards a New Cosmopolitan Anthropology'. In P. Werbner (ed.) Anthropology and the New Cosmopolitanism: Rooted, Feminist and Vernacular Perspectives. Oxford: Berg Publishers, pp. 1-32. 